\section{ESCRIBIR LA HISTORIA: ACTIVISMO EN WIKIPEDIA Y EL DEBATE POR LA DESPENALI- ZACIÓN DEL ABORTO EN ARGENTINA}

\author{
Paloma Rubin \\ Universidad Nacional de Villa María, Argentina \\ orcid: 0000-0002-5222-9523 \\ palomarubin12@gmail.com
}

\section{W/RITING HISTORY: ACTIVISM IN WIIKIPEDIA AND THE DEBATE FOR DECRIMINALIZATION OF ABORTION IN ARGENTINA}

\author{
Agustín Zanotti \\ Universidad Nacional de Córdoba/ CONICET \\ Universidad Nacional de Villa María, Argentina \\ orcid: 0000-0002-7662-7593 \\ azanotti@unvm.edu.ar
}

Para citar este artículo:

Rubin, P. \& Zanotti, A. (2019). Escribir la Historia: activismo en Wikipedia y el debate por la despenalización del aborto en Argentina. Commons. Revista de Comunicación y Ciudadanía Digital, 8(2), 122-158. http://dx.doi.org/10.25267/COMMONS.2019.v8.i2.04

Fecha de recepción: 05/03/2019. Fecha de aceptación: 15/05/2019

\section{Resumen}

El trabajo analiza procesos de producción colaborativa en la enciclopedia libre Wikipedia, tomando el caso del artículo Aborto en Argentina de su edición en español. El debate generado durante el tratamiento legislativo en 2018 del Proyecto de ley de Interrupción Voluntaria del Embarazo (ILE), implicó una fuerte movilización de la opinión pública en una disputa entre posiciones proelección y provida. Todo ello en un ecosistema tecnocomunicacional donde conviven plataformas de software social con medios de masas. El análisis se desarrolla en cuatro ejes: 1 . evolución del artículo; 2. perfil de ediciones y editores; 3 . discusiones y controversias; 4 . uso de fuentes para validación del contenido. El artículo se sustenta en un análisis cuanti-cualitativo de datos disponibles en la plataforma, alimentando una reflexión sobre métodos digitales.

\section{Palabras clave}

Wikipedia, aborto, software social, producción colaborativa

\begin{abstract}
The paper analyzes processes of collaborative production in Wikipedia, the free encyclopedia, taking the case of the article Aborto en Argentina (Abortion in Argentina) of its Spanish edition. The debate generated during a bill treatment on Voluntary Interruption of Pregnancy in 2018, implied a strong mobilization of public opinion in a dispute between "pro-choice" and "pro-life" positions. All this within a techno-communication ecosystem where social software platforms coexist with mass media. Presentation is developed in four areas: 1 . evolution of the article; 2. editions and editors profile; 3. discussions and controversies; 4. sources usage for content validation. The article is based on a quantitative-qualitative analysis of available data on the platform, fueling a reflection on digital methods.
\end{abstract}

\section{Keywords}

Wikipedia, abortion, social software, collaborative production 


\section{Introducción}

Wikipedia es un ejemplo de producción colaborativa a nivel global. Creada en 2001, se despliega hasta la actualidad incorporando numerosos proyectos y ediciones idiomáticas. La enciclopedia se inspira en principios de cultura libre, iniciados por los movimientos de software libre. Su constitución como fundación sin fines de lucro y su funcionamiento basado en la colaboración en masa de miles de voluntarios, alimenta el ideal de libertad de la información y el conocimiento que constituye internet (Zanotti, 2014). El proyecto propone como lema albergar "la suma del conocimiento humano" (WMF, 2018) y contiene artículos de diversas temáticas. Cualquiera puede contribuir en su edición, respetando un conjunto de normas y principios. Uno de ellos es el criterio de "punto de vista neutral", basado en la verificabilidad y la ausencia de trabajos inéditos.

Wikipedia ocupa un lugar central en un ecosistema dinámico de medios conectivos (Van Dijck, 2016). Según datos de la propia enciclopedia, solo en Argentina se visualizan mensualmente más de 150 millones de artículos (WMF, 2018, 3 de noviembre). Ford (2015) sostiene que la misma puede entenderse como una "fábrica de hechos", en la medida en que ha devenido una fuente de autoridad. Esto se debe a una serie de procesos, entre los que destacan la revalorización de una idea de sabiduría colectiva (inspirados por los principios de código abierto y la ley de Torvalds ${ }^{1}$ ), así como alianzas con actores corporativos, que posicionan a Wikipedia como un contenido destacado entre los resultados de los principales buscadores web (Van Dijck, 2016).

1. Se trata de la afirmación de Linus Torvalds, elaborada como principio por Raymond, que dice: "Given enough eyeballs, all bugs are shallow" (Dado un número elevado de ojos, todos los errores se vuelven obvios) (2001: 19). La misma sintetiza una de las virtudes del modelo abierto (open source), aplicada a la producción de software y trasladada luego hacia otros dominios. 
El artículo analiza la producción del artículo Aborto en Argentina de la edición en español de Wikipedia. El fuerte debate social generado en 2018 durante el tratamiento del proyecto de legalización de aborto, generó una necesidad de movilizar la opinión pública tanto por activistas en favor y en contra de la iniciativa. Estas dinámicas pueden entenderse desde teorías de los movimientos sociales (Bennett, 2005; Castells, 2007; Tilly \& Wood, 2010), siguiendo una disputa de movimiento-contramovimiento social. Dentro de esta, diferentes estrategias fueron utilizadas para promover las posiciones y argumentos proelección y provida ${ }^{2}$. Todo ello en un escenario tecnocomunicacional donde conviven plataformas de software social con medios de comunicación de masas.

Como veremos, la edición de Aborto en Argentina y su visualización crecieron exponencialmente durante el periodo en consideración, dando lugar a numerosas dinámicas colaborativas. El análisis se desarrolla en cuatro ejes: 1. evolución del artículo y tendencias; 2 . perfil de ediciones y editores principales; 3 . discusiones y controversias; 4 . uso de fuentes y validación del contenido.

El caso planteado permite ponderar la importancia de Wikipedia en un creciente contexto de políticas de post-verdad (Benkler, Faris \& Roberts, 2018), donde la red global, lejos de multiplicar puntos de vista, parece generar una clausura sobre los propios pensamientos y emociones.

2. Este término deriva de la entrada anglosajona pro-choice. En el caso argentino se utilizó frecuentemente el término "proaborto" para designar la despenalización de la interrupción voluntaria del embarazo. La definición fue fuertemente discutida dentro del movimiento, intentando vincularse a expresiones como "proderechos o a favor del aborto legal". La apropiación del término vida fue una estrategia del sector contrario a la ley, por lo que las feministas nombraban proaborto legal vs. clandestino (Piñeiro, 2018, 12 de abril). 


\section{Metodología}

La propuesta se nutre de desarrollos recientes sobre métodos digitales y su relevancia para la comprensión de fenómenos culturales contemporáneos. Algunas de las aproximaciones más populares son la analítica de grandes datos (Manovich, 2011), así como las etnografías de internet, con sus variantes (Hine, 2015). Lejos de tratarse de abordajes excluyentes, presentan nuevas posibilidades de triangulación entre datos agregados y datos profundos, lo cual contribuye a una mejor comprensión del funcionamiento de las plataformas y las interacciones cotidianas de los usuarios (Ardévol, 2016). Dentro de los métodos digitales, destaca el potencial de las nuevas fuentes presentes en internet y las huellas de la actividad de los usuarios, lo cual ha desplegado una serie de innovaciones desde las ciencias sociales, al tiempo que evidencia una creciente necesidad de trabajo transdisciplinario (Snee et al., 2016).

Wikipedia es una plataforma abierta y ofrece una política de acceso a los datos generados, en vistas a garantizar su transparencia y auditabilidad. Para ello, ha desarrollado herramientas analíticas que permiten el seguimiento de la evolución de sus artículos, las contribuciones de los editores y las visualizaciones por parte de los usuarios. También se han desarrollado un conjunto de herramientas comunitarias que facilitan tareas de investigación o requerimientos específicos. 
El artículo se sustenta en un análisis cuanti-cualitativo de datos disponibles en la plataforma. Para ello se utilizaron las herramientas estadísticas de Wikimedia (versión 1 y 2) y Wikimedia Toolforge XTools ${ }^{3}$, aplicadas al artículo Aborto en Argentina de la edición en español. Para la parte cuantitativa se utilizaron métricas de evolución del artículo en tamaño y cantidad de ediciones, así como contribuciones de los principales usuarios. La parte cualitativa se basa en el análisis de la sección de discusión que acompaña al artículo, así como el historial de ediciones. Utilizamos herramientas metodológicas del análisis del discurso para identificar posturas que se construyen en los distintos debates. Tomamos los postulados de Angenot (2010) para comprender que ningún discurso es neutral, sino que debe ser entendido como un discurso social, es decir situado en relaciones de poder que deben ser historizadas y situadas. También se llevó a cabo una clasificación de las fuentes utilizadas, para determinar su tipo y diversidad. Los datos comprenden el ciclo de vida del artículo, desde su creación en abril de 2009 hasta septiembre de 2018.

\section{Sobre Wikipedia y el punto de vista neutral}

Autores como Konieczny (2010), se refieren a Wikipedia como una adhocracia, donde el objetivo es compartir conocimiento. Sus procesos de toma de decisiones se asemejan al concepto de gobernanza entre pares propuesto por Bauwens (2008). Van Dijck (2016) ubica Wikipedia en una posición de "soledad en la cima" dentro del ecosistema de medios conectivos. La legitimidad y autoridad que le ha sido conferida no entra en competencia con otras plataformas comerciales, sino que más bien complementa sus modelos de negocio. A diferencia de otras plataformas de software social, en este caso las ediciones no son efímeras sino hechas para durar, y esto orienta de modo fundamental el comportamiento de los usuarios.

3. Para una visualización en tiempo real de tendencias generales: https:/xtools.wmflabs.org/articleinfo/ es.wikipedia.org/Aborto\%20en\%20Argentina?uselang=es 
Wikipedia se basa en un proceso incremental de desarrollo y autocorrección, basado en importante medida en la edición amateur (Benkler, Shaw \& Hill, 2015). Esto quiere decir que los artículos se van desarrollando a través de un proceso continuo de revisión y reescritura parcial. El promedio de Wikipedia en español al momento del estudio (septiembre de 2018) es de 57 ediciones por artículo (WMF, 2018, 3 de noviembre).

Más allá de esto, la enciclopedia mantiene un desorden propio de la creación en masa: guerras de edición, reversiones, vandalismo, lagunas y sobreabundancia de información. Las versiones idiomáticas mantienen autonomía relativa y pueden desarrollar reglas y procedimientos propios, tales como criterios para tratar el vandalismo, temas sensibles, utilización comercial o de propaganda (Lerga Felip \& Aibar Puentes, 2015: 2). Gran parte de las tareas de edición —en general de rutina o mantenimiento, aunque también creación de artículos- son realizadas de manera automatizada. Cada edición idiomática tiene sus propios bots ${ }^{4}$, los cuales son creados y discutidos por la comunidad. Esto la convierte en un caso paradigmático de coexistencia entre humanos y no-humanos, donde ambos asumen cualidad de actantes, utilizando el término propuesto por Latour (2008).

Wikipedia es una comunidad organizada en base a cinco pilares: 1 . es una enciclopedia; 2. busca el «punto de vista neutral»; 3. es de contenido libre; 4. sigue normas de etiqueta (referidas a pautas de comportamiento cordial); 5. no tiene normas firmes (Wikipedia, s.f). Como anticipamos, la validez del contenido se sostiene en el principio de neutralidad, el cual ha dado lugar a numerosas polémicas:

\footnotetext{
4. Un bot (aféresis de robot) es un programa informático que efectúa automáticamente ediciones repetitivas, cuya realización por parte de una persona sería imposible o muy tediosa.
} 
Editar desde un punto de vista neutral (PVN) significa reflejar de manera justa, proporcionada $\mathrm{y}$, en la medida de lo posible, sin sesgo, todos los puntos de vista significativos que hayan sido publicados por fuentes fiables. (...) No supone que sea posible escribir un artículo desde un único punto de vista objetivo no sesgado. Dice que debemos representar adecuadamente los diferentes puntos de vista y sin que el artículo afirme, implique o insinúe que alguno de ellos es el correcto. (Wikipedia: políticas y convenciones, 2018)

Neutralidad no es en este caso sinónimo de verdad objetividad, sino de reflejar la diversidad de puntos de vista, basados en dos elementos centrales: "Verificabilidad: debe poderse comprobar que la información añadida ha sido publicada por otras fuentes autorizadas. Ausencia de trabajos inéditos: Wikipedia no publica información original ni trabajos inéditos (material no publicado, ensayos, resultados parciales de investigaciones en curso)" (Lerga Felip \& Aibar Puentes, 2015: 2).

Si observamos las políticas definidas por Wikipedia en español, encontramos que se basan en el uso de "fuentes fiables, independientes y publicadas", otorgando precisiones sobre cada uno de estos términos (Wikipedia: Fuentes fiables). Se recomienda además el uso de fuentes secundarias sobre primarias o terciarias:

Los artículos de Wikipedia deben basarse en fuentes secundarias fiables. Las fuentes primarias pueden considerarse fiables en algunas ocasiones, pero no de forma general. Cuando se usen fuentes primarias, deberá hacerse con precaución, pues es fácil, por ejemplo, tomar varias de ellas de forma selectiva, intencionalmente o no, y construir a partir de estas una investigación original que contradiga o sustituya a las fuentes secundarias fiables. (...) Una fuente secundaria es siempre preferible a una fuente terciaria (enciclopedias basadas en fuentes secundarias, compendios, libros de texto o escolares y otras fuentes recopilatorias). (Wikipedia: políticas y convenciones, 2018) 
En concordancia con lo anterior, la enciclopedia presenta restricciones para el uso de fuentes periodísticas ${ }^{5}$ o autopublicaciones ${ }^{6}$. Otros lineamientos son definidos por la negativa, delimitando lo que Wikipedia no es. Entre ellos encontramos:

\begin{abstract}
Wikipedia no es una tribuna de opinión. Wikipedia no es un lugar para defensas de ideas, proselitismos, propaganda o publicidad. Por tanto, los artículos de Wikipedia no son: 1. Propaganda o defensas de ideas de ningún tipo. (...) 2. Autopromoción y autobiografía. (...) 3. Publicidad. (...) 4. Foros de discusión. (Wikipedia: políticas y convenciones, 2018)
\end{abstract}

Estas políticas son especialmente relevantes en casos de controversias. Tal y como sostienen desde el proyecto Contropedia (2018), la creación de contenido colaborativo inevitablemente llega a situaciones en las que diferentes puntos de vista generan conflictos. El mismo está mediado por políticas y software, a menudo reflejando debates sociales más amplios. La plataforma prevé en este sentido cuatro mecanismos de interacción: 1. comunicación intra-artículos (páginas de discusión); 2. comunicación entre usuarios (páginas de discusión de usuarios); 3. formación de proyectos y grupos de trabajo; 4. discusión de políticas y procedimientos. Junto a ello existen una serie de mecanismos para alcanzar consensos, como políticas de mediación, arbitraje y apelación.

5. "Las fuentes especializadas deben tener prioridad sobre la prensa generalista, ya que diarios y semanarios tienden a simplificar su exposición, omitiendo a veces datos importantes o describiendo el tema de forma enciclopédicamente poco útil, al dirigirse a un público más amplio que no tiene por qué dominar la disciplina" (Wikipedia: políticas y convenciones, 2018).

6. “...libros autopublicados, fanzines, páginas webs personales, blogs, foros de discusión, redes sociales, wikis abiertas, knoles, podcasts, entre otros medios de información no formales, sobre todo en lo referente a opiniones o análisis del tema tratado, no sean aceptables, salvo que sean obra de personas o entidades de autoridad ampliamente reconocida en el tema, su contenido se base en fuentes acreditadas o sean citados para verificar información sobre sí mismos" (Wikipedia: políticas y convenciones, 2018). 
Se busca de tal modo que la confrontación de argumentos permita arribar a consensos, siempre basados en el seguimiento de las normas que rigen la plataforma. La confianza recíproca y la "buena fe" son, de este modo, fundamentales para mantener un equilibrio en la comunidad (Reagle, 2010). Esta se sostiene en procesos ordenados y transparentes, que permiten su auditabilidad (Jemielniak, 2014).

\section{El debate por el aborto legal en Argentina}

Nos acercamos al debate por la legalización del aborto desde una definición de movimientos sociales. Tilly los define como "una interacción sostenida entre detentadores del poder y activistas que hablan a favor de una población agraviada, a través de públicas y colectivas manifestaciones de determinación y capacidad acompañadas con un explícito apoyo a programas de acción" (Tilly, 2000: 17). Su movilización apunta a la visibilización de un conflicto y la corrección de una injusticia. Sus manifestaciones de solidaridad buscan resaltar la dignidad de los reclamos, así como la unidad, el compromiso y la amplitud de los colectivos que lo conforman.

Numerosos estudios coinciden en la importancia de internet y las TIC para la organización y difusión de los movimientos sociales (Bennett, 2005; Castells, 2007; Tilly \& Wood, 2010). Castells (2007) enfatiza la relación entre comunicación y poder, la cual cobra una renovada centralidad en el momento actual. Siguiendo a este autor, la capacidad de influir sobre la opinión pública se constituye en herramienta principal para legitimar decisiones políticas. Esto aparece patente en los casos de ampliación de derechos femeninos y de género, donde es habitual que se generen corrientes de oposición. Nos referimos a ellas con el término contramovimiento, definidos por McCarthy y Zald como un "conjunto de opiniones y creencias de un grupo que se opone a un movimiento social" (citado por i Pérez, 2007). 
El feminismo como movimiento social en Argentina tiene una larga trayectoria de lucha y organización. Como demuestra Barrancos (2007) la organización feminista históricamente tuvo una base fuerte de partidos políticos y puja por leyes de potestad a las mujeres. Fue la crisis económica, política y social de 2001, la que sirvió para fortalecer la organización territorial de base, gracias a las acciones colectivas cotidianas llevadas a cabo por mujeres (Echavarría \& Bard Wigdor, 2013). El movimiento feminista se fortaleció, impulsando ciertas leyes sancionadas a lo largo del período kirchnerista, como la Ley de Educación Sexual Integral en 2006, la Ley contra la Trata de Personas en 2008, la Ley de Protección Integral para Prevenir, Sancionar y Erradicar la Violencia Contra las Mujeres en 2009, la Ley de Matrimonio Igualitario en 2010 y Ley de Identidad de Género en 2012. En su conjunto, posicionaron a Argentina dentro de los países pioneros en legislaciones de género a nivel global (Peker, 2017).

Tres momentos principales dan forma al último ciclo de protesta feminista en Argentina: el Encuentro Nacional de Mujeres (ENM) (1986), la Campaña por el Aborto Legal Seguro y Gratuito (2005) y el \#NiUnaMenos (2015). El ENM es un encuentro que se realiza anualmente en un punto cambiante del país. Es el punto de confluencia de todas las organizaciones feministas y de mujeres, y ha ido cambiando y creciendo a lo largo de la historia (en 1986 eran 1000 asistentes y en 2015 llegó a 65.000). Se realizan talleres como espacios horizontales de debate en torno a un tema particular y su relación con las mujeres. De estos surgen las demandas feministas más importantes y sirve también como muestra de análisis (ENM, 2018). ${ }^{7}$

\footnotetext{
7. La votación final en la Cámara de Senadores fue el 8 de agosto, mientras que el ENM de 2018, el 15 de octubre. Se desarrollaron los talleres dedicados a pensar el tema, pero este año la concurrencia fue masiva superando los límites físicos de las escuelas destinadas a contenerlos. Los talleres fueron: Mujeres y derechos sexuales y reproductivos, Mujeres, anticoncepción y aborto, y el estelar, Estrategias para el Acceso al Aborto Legal, Seguro y Gratuito (Bellucci, 2014).
} 
A partir de una militancia sostenida del colectivo feminista, desde los talleres en el ENM en 2003 y 2004, se lanza en 2005 la Campaña por el Aborto Legal Seguro y Gratuito. El Proyecto de Interrupción Legal del Embarazo, que terminó de delinearse de manera colectiva en 2006, fue presentado en los años 2007, 2009, 2010, 2012, 2014, 2016 y 2018, cuando accedió efectivamente a la instancia de debate y votación en las cámaras de Diputados y Senadores. La lucha por el Aborto Legal, Seguro y Gratuito se convirtió en un estandarte de lucha feminista, y el pañuelo verde de la Campaña, en un símbolo ${ }^{8}$ (Bellucci, 2014).

Para contextualizar brevemente, en América del Sur el aborto solo es legal en Uruguay, donde la tasa de mortalidad materna es de 14 mujeres cada 100.000 nacidos vivos, contra 55 en Brasil -en donde está totalmente prohibido-y 52 en Argentina. En algunos países, entre ellos Argentina desde 2015, puede accederse a un aborto con causales, es decir, si ese embarazo es fruto de una violación o afecta a la salud de la mujer (Amnistía Internacional, 2018). Sin embargo, y especialmente hasta que el aborto se puso en el centro de la discusión pública, este Protocolo para la Atención Integral de las Personas con Derecho a la Interrupción Legal del Embarazo (Protocolo ILE) estuvo muy poco difundido, y su aplicación es todavía discrecional.

En la última década se luchó desde las organizaciones feministas y a través de las redes sociales por un correcto tratamiento mediático de la violencia machista y los crímenes de género como feminicidio y no como crimen pasional. El 3 de junio de 2015 fue la primera marcha \#NiUnaMenos, con una masividad que se replicó en todo el país. Famosos del ámbito artístico, deportivo, televisivo y personalidades políticas del más amplio espectro ideológico apoyaron la consigna en redes sociales a través del hashtag (Alamo et al., 2018).

\footnotetext{
8. La Campaña Legal por el Aborto Legal, Seguro y Gratuito tiene como lema "Educación Sexual para decidir, anticonceptivos para no abortar, aborto legal para no morir", para destacar el carácter integral de las reformas propuestas (Bellucci, 2014). Siguiendo la línea de Madres de Plaza de Mayo, referentes de lucha y organización histórica en Argentina, se toma el símbolo del pañuelo en verde, con el logo y el lema de la campaña en un círculo.
} 
Desde entonces se repite anualmente y crece su número de asistentes. Lo importante del \#NiUnaMenos es que el nivel de adhesiones que implicó, forjó un cambio cultural profundo del feminismo en Argentina. Los Encuentros de Mujeres se volvieron masivos, el feminismo se legitimó y encontró aceptación en sectores más amplios. La Ley de Medios y la Ley para erradicar la violencia contra las mujeres y las niñas tuvieron su parte en la responsabilidad. El trabajo conjunto de actrices y periodistas en los medios hegemónicos, otra.

En los primeros meses de 2018 el tema de violencia hacia las mujeres recobra una fuerte presencia en la agenda pública y mediática. Ante una avalancha de cruces en las redes sociales entre famosos de televisión, denuncias por acoso en programas, obras de teatro y cine, el programa Intrusos en el espectáculo ${ }^{9}$ interpela directamente esas denuncias y dedica varias horas de sus emisiones diarias a hablar sobre feminismo, con invitadas feministas que explicaron en vivo y por primera vez cómo realizar un aborto seguro.

El 8 de marzo, en el Día Internacional de la Mujer, se organizó un paro general y marcha masiva con el eslogan "Si nuestra vida no vale, produzcan sin nosotras". Esta fecha obtuvo una trascendencia y réplica a nivel mundial. Como demanda clave estaba la legalización del aborto, en días previos al inicio de su tratamiento legislativo. Desde el 20 de marzo el Proyecto de Ley de régimen de interrupción voluntario del embarazo comenzó a tratarse en la Cámara de Diputados. El mismo proponía el aborto libre como un derecho hasta la semana 14 de embarazo, y hasta el final del embarazo en tres causales (violación; peligro para la vida/salud física, psíquica y social de la madre; malformaciones fetales graves). Incluía además al aborto en el Programa Médico Obligatorio (Expte. 230-D-2018).

9. Intrusos en el espectáculo es el programa líder de Argentina dedicado a discutir la vida privada de las celebrities del espectáculo. Tiene un gran peso mediático y específicamente, la capacidad de formar agenda en relación con los demás programas de éste formato (Justo Von Lurzer, 2017). 
En todo el país se organizaron marchas y contramarchas, siendo las primeras claramente mayoritarias. El pañuelo verde se popularizó como símbolo de la adhesión al proyecto, y el término marea verde para denominar esta organización masiva sobre todo de jóvenes (Sin Permiso, 2018). El grupo provida, por su lado, contó con el apoyo de instituciones religiosas, algunos colegios médicos, figuras mediáticas y referentes de la política. Se identificó por su pañuelo celeste, similar a la bandera patria, con la consigna estampada: "Salvemos las dos vidas". Otro de sus símbolos en la movilización fue la escultura gigante "el bebito", y sus réplicas para colgar en balcones o usar como llavero (Rosende \& Pertot, 2018).

El 13 de junio se inició la votación en una noche de vigilia cargada de expectativas, donde la sesión se estiró toda la noche y la votación fue el 14 de junio a la mañana. La votación resultó positiva y avanzó a la Cámara de Senadores. Las audiencias públicas en el Senado se sostuvieron hasta su votación el 8 de agosto. Las marchas y la vigilia se replicaron, divididas frente a la Cámara en verdes y celestes por una valla. Esta votación tuvo resultado negativo, por lo que el proyecto por un aborto no punible no fue sancionado y se pasó a un cuarto intermedio hasta 2019.

\section{El artículo: Aborto en Argentina}

Luego de establecido el abordaje y los principales términos de la investigación, nos abocamos al análisis del artículo en la edición en español de Wikipedia, para lo cual tomamos cuatro ejes: 1 . evolución del artículo y tendencias; 2 . el perfil de ediciones y editores principales; 3 . discusiones y controversias; 4 . uso de fuentes y validación del contenido presentado. 
Como anticipamos, el artículo en cuestión se refiere a hechos recientes, que marcaron fuertemente las agendas públicas y mediáticas en el marco del proyecto de ley por la legalización del aborto en Argentina. Encontramos en este artículo un interés por parte de los editores por visibilizar posiciones o argumentos proelección o provida, los cuales deben - al mismo tiempo- ajustarse a los principios definidos por Wikipedia. En este tipo de casos, la enciclopedia habilita una serie de plantillas que advierten sobre la particularidad de que se trata de temas de actualidad y sujetos a controversias, intentando con ello moderar y orientar las ediciones, anticipando sobre posibles cambios en el contenido, lagunas, sesgos o incorrecciones.

\section{Imagen 1}

Plantillas $\{$ \{actualidad $\}\{\{$ polémico $\}\}$

\begin{tabular}{|l|l|}
\hline 12 & $\begin{array}{l}\text { Este artículo o sección se refiere o está relacionado con } \\
\text { un evento reciente o actualmente en curso. } \\
\text { La información de este artículo puede cambiar } \\
\text { frecuentemente. Por favor, no agregues datos } \\
\text { especulativos y recuerda colocar referencias a fuentes } \\
\text { fiables para dar más detalles. }\end{array}$ \\
\hline 1 & $\begin{array}{l}\text { Este es un tema polémico, que puede estar disputado. } \\
\text { Por favor lee esta página de discusión y discute cambios } \\
\text { importantes antes de hacerlos. Asegúrate de incluir } \\
\text { referencias cuando añadas información. }\end{array}$ \\
\hline
\end{tabular}

Fuente: es.wikipedia.org 


\subsection{Evolución del artículo}

Aborto en Argentina se creó en abril de 2009 y presenta unas 1650 ediciones hasta septiembre de 2018, momento del análisis. De estas, más de 1200 fueron realizadas durante el mes previo y durante el tratamiento legislativo del proyecto de legalización (WMF, 2018, 3 de noviembre). El artículo llegó con ello a ubicarse dentro de los 4000 más editados de la Wikipedia en español (Artículos con más ediciones, 2018, 3 de octubre).

El artículo en su versión actual presenta la siguiente estructura: la sección 1 es introductoria, proporcionando una definición del estatus legal de la práctica de aborto en Argentina. La sección 2 incluye una historización de los primeros códigos penales hasta la actualidad, prestando especial atención a los casos contemplados de práctica legal, así como fallos y jurisprudencia relevante. También se suman declaraciones de organismos internacionales en relación al caso argentino. La sección 3 es una síntesis de protocolos vigentes en caso de abortos no punibles, sus definiciones y cambios recientes. La sección 4 presenta un panorama de su implementación a nivel provincial. Tratándose de una ley nacional, la ratificación y alcance de la misma puede variar en cada jurisdicción. Se incluyen luego en la sección 5 un conjunto de series estadísticas sobre la incidencia del aborto a nivel poblacional, su relación con causa de muerte materna y sondeos de opinión pública sobre su legalización. Las secciones 6 y 7 se dedican a detallar referentes y organizaciones en favor y en contra de la legalización del aborto, incluyendo aquellas del ámbito académico, religioso, político, artístico, la sociedad civil e internacionales.

Al revisar el historial de ediciones, encontramos que tal estructura se fue estabilizando a lo largo del tiempo, abonando el principio sostenido por la enciclopedia de mejora incremental de su contenido. De hecho, ninguna de las secciones actuales formaban parte de su formulación inicial en 2009. La Tabla I muestra los cambios en la estructura del artículo a lo largo del tiempo, tomando cuatro imágenes sincrónicas. 
Tabla I

Estructura del artículo Aborto en Argentina (versiones seleccionadas)

\begin{tabular}{|c|c|c|c|}
\hline 9 abril 2009 & 11 julio 2011 & 13 julio 2014 & 1 septiembre 2018 \\
\hline $\begin{array}{l}\text { 1. La ley y el debate } \\
\text { público } \\
\text { 2. Referencias } \\
\text { 3. Véase también }\end{array}$ & $\begin{array}{l}\text { 1. Excepciones a } \\
\text { la penalización del } \\
\text { aborto } \\
\text { 2. Número de } \\
\text { abortos en } \\
\text { Argentina } \\
\text { 3. La ley y el debate } \\
\text { público } \\
\text { 4. Aborto no } \\
\text { punible } \\
\text { 5. Referencias } \\
\text { 6. Véase también } \\
\text { 7. Enlaces externos }\end{array}$ & $\begin{array}{l}\text { 1. Guía técnica para } \\
\text { la atención integral } \\
\text { de los abortos no } \\
\text { punibles } \\
\text { 2. Historia de la } \\
\text { legislación del } \\
\text { aborto } \\
\text { 3. El debate } \\
\text { público: sanciones, } \\
\text { fallos judiciales y } \\
\text { declaraciones } \\
\text { 3.1 Organizaciones } \\
\text { pro elección } \\
\text { 3.2 Organizaciones } \\
\text { pro vida } \\
\text { 4. Véase también } \\
\text { 5. Notas } \\
\text { 6. Referencias } \\
\text { 7. Enlaces externos }\end{array}$ & $\begin{array}{l}\text { 1. Estatus legal } \\
\text { 2. Historia de la } \\
\text { legislación del } \\
\text { aborto } \\
\text { 3. Guías y } \\
\text { protocolos para } \\
\text { la realización de } \\
\text { abortos no punibles } \\
\text { 4. Situación de } \\
\text { los protocolos } \\
\text { provinciales para } \\
\text { la atención de los } \\
\text { abortos no punibles } \\
\text { 5. Estadísticas } \\
\text { 6. Organizaciones } \\
\text { contrarias a la } \\
\text { legalización del } \\
\text { aborto } \\
\text { 7. Organizaciones a } \\
\text { favor del derecho al } \\
\text { aborto } \\
\text { 8. Véase también } \\
\text { 9. Notas } \\
\text { 10. Referencias } \\
\text { 11. Enlaces } \\
\text { externos }\end{array}$ \\
\hline
\end{tabular}

Fuente: elaboración propia, en base a Aborto en Argentina (2018, 3 de octubre) 
Un proceso de polarización del contenido puede observarse a partir del peso relativo de las secciones Organizaciones contrarias a la legalización del aborto y Organizaciones a favor del derecho al aborto, las cuales fueron incrementando su volumen hasta la actualidad. Ambas secciones mantienen, sin embargo, cierta simetría a lo largo del tiempo - no sin controversias respecto de su contenidolo cual evidencia una adecuación al principio de punto de vista neutral.

Otras secciones aparecieron y fueron descartadas durante el ciclo de vida del artículo, referidas a Casos emblemáticos y Manifestaciones populares hacia ambos lados de la movilización social. Estas últimas se iban nutriendo especialmente de acontecimientos de coyuntura, con fuentes periodísticas como anclaje principal. Junto con ello surgen artículos derivados, como es el caso de Proyecto de Ley de Interrupción Voluntaria del Embarazo en Argentina. Originado como sección dentro del artículo principal, luego se constituye como artículo separado en agosto de 2018.

Se observa además el crecimiento paralelo de artículos relacionados, como Debate sobre el aborto, Legislación sobre la práctica del aborto en el mundo y Aborto inducido, entre otros. Asimismo encontramos artículos sobre aborto referidos a 69 casos nacionales, con diferente grado de desarrollo, lo cual evidencia una cobertura exhaustiva sobre la problemática ${ }^{10}$. Aborto en Argentina cuenta a su vez con entradas en otras ediciones idiomáticas como asturiano, inglés, francés y portugués, lo que incrementa su visibilidad internacional. Cabe aclarar que el traspaso de entradas hacia otros idiomas no se efectúa de forma automática, lo que implica en cada caso una nueva reelaboración.

10. Véase Categoría: Aborto por país en es.wikipedia.org. 
En concordancia con lo presentado en la sección anterior, los datos agregados sobre cantidad de ediciones y volumen evidencian un crecimiento exponencial del artículo en el mes previo y los inmediatos al debate legislativo, coincidente además con una fuerte instalación del tema en las agendas mediáticas. Las figuras 1 y 2 , muestran que el volumen y cantidad de ediciones durante los meses de febrero a septiembre de 2018 superan a la totalidad de ediciones realizadas hasta ese momento, produciéndose el pico máximo durante el mes de marzo.

\section{Figura 1}

Cantidad de ediciones y volumen del artículo (2009-2018)

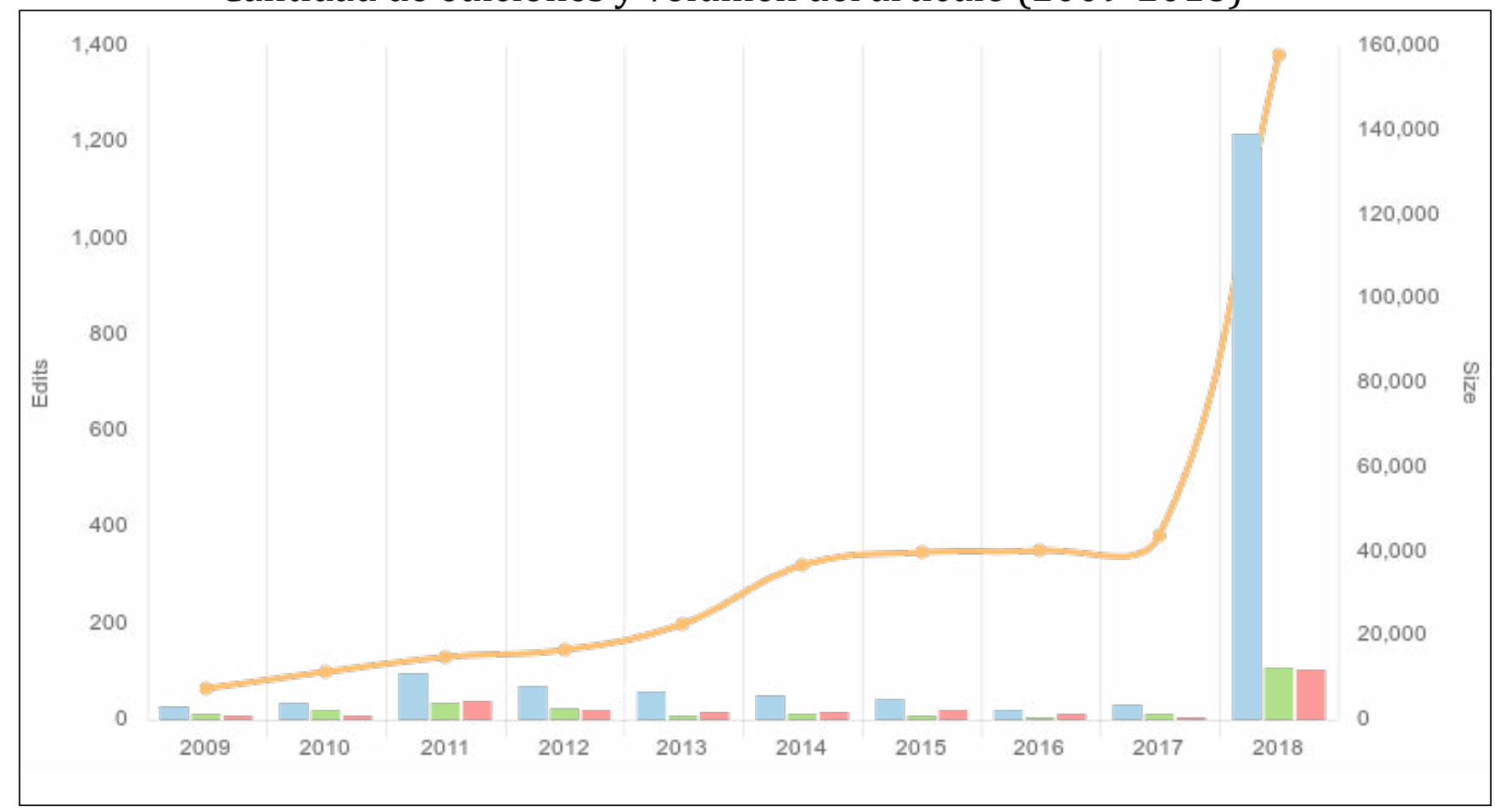

Ediciones totales $\bigcirc$; Ediciones menores $\bigcirc$; Ediciones anónimas $\bigcirc$; Tamaño $\bigcirc$

Fuente: elaboración propia, en base a Aborto en Argentina (2018, 3 de octubre) 
Otro dato a destacar es que la cantidad de ediciones menores (inferiores a 50 caracteres) así como ediciones realizadas por editores anónimos son inferiores al promedio de artículos ${ }^{11}$ (WMF, 2018, 3 de noviembre). Ello podría denotar un fuerte nivel de involucramiento por parte de los editores, al presentar su propia identidad y aportar cantidades significativas de contenido en cada contribución. Profundizamos sobre este argumento en la siguiente sección.

Encontramos tres momentos pico en la cantidad de ediciones: febrero/marzo, 13 de junio y 8 de agosto. La actividad disminuye a partir de que el Proyecto es rechazado en el Senado.

\section{Figura 2}

Cantidad de visualizaciones (septiembre 2017-agosto 2018)

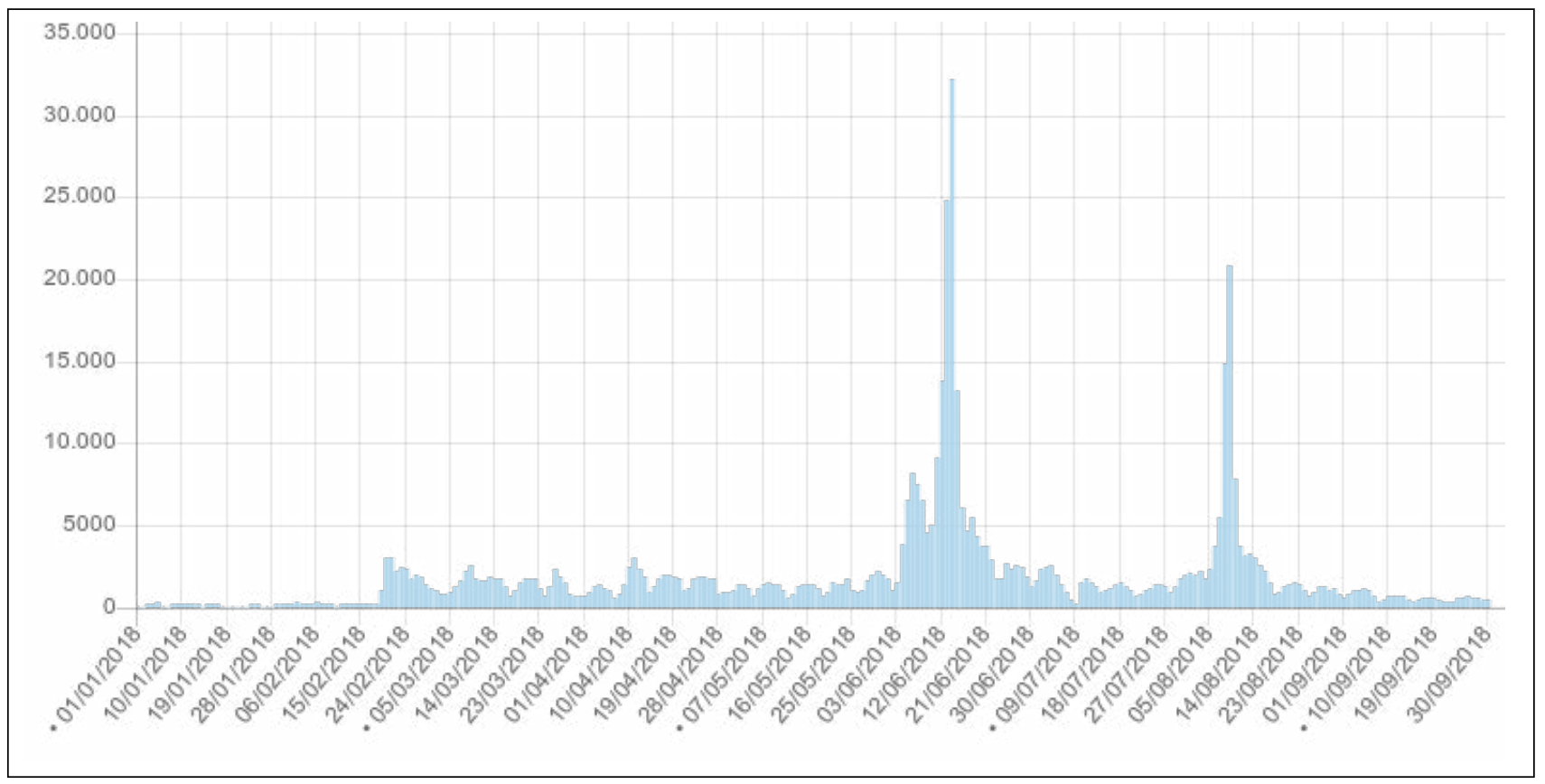

Fuente: elaboración propia, en base a Aborto en Argentina (2018, 3 de octubre)

11. Según estadísticas provistas por la Wikipedia, las ediciones realizadas por usuarios no registrados en la edición en español corresponden a un $37 \%$ del total. 
Un tercer aspecto es el incremento de la visualizaciones del artículo, las cuales acompañan el incremento en las ediciones durante el periodo febrero-septiembre de 2018. Esto evidencia la colocación del tema en la agenda pública y mediática, generando una multiplicación por ocho para el conjunto del periodo (desde 8.297 a 67.756 visualizaciones mensuales) y por 22 en el mes de junio (186.136 visualizaciones). En su conjunto, el artículo fue visualizado 491.493 veces en el periodo previo, durante y posterior al debate parlamentario.

\subsection{Los editores}

Aborto en Argentina fue editado por 296 personas desde su creación en 2009 (WMF, 2018, 3 de noviembre). Encontramos sin embargo una distribución en forma piramidal, siguiendo la regla 90-9-1 de desigualdad participativa, en la que los usuarios activos (9\%) y muy activos $(1 \%)$ constituyen la parte superior, mientras la mayoría (90\%) solo realiza contribuciones menores o consume información (Nielsen, 2006). En otras palabras, encontramos un núcleo de colaboradores que realizaron la mayor parte de ediciones y un número amplio de editores ocasionales, tal como se muestra en la Figura 3.

\section{Figura 3}

Atribución de autoría: Aborto en Argentina*

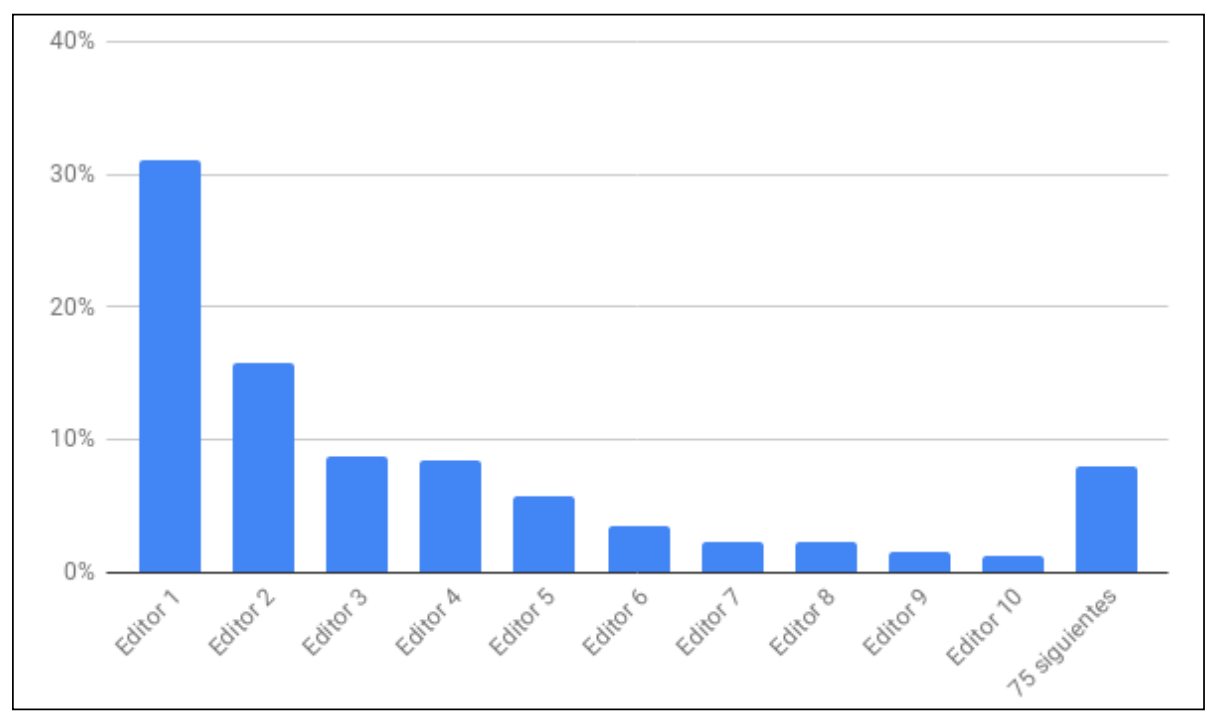

* medida por recuento de caracteres, incluyendo espacios

Fuente: elaboración propia, en base a Aborto en Argentina (2018, 3 de octubre) 
Otra particularidad que denota el alto involucramiento de los editores es la inclusión de información personal en sus páginas de usuario. Wikipedia otorga a cada usuario un espacio personal que puede configurarse libremente y en donde pueden añadirse preferencias y referencias ideológicas. Desde la enciclopedia se argumenta que ello contribuye al principio de punto de vista neutral, ya que permite explicitar los sesgos personales de cada editor.

Una forma habitual de realizar estas presentaciones es mediante el uso de plantillas creadas por la comunidad. Encontramos en este sentido que los autores con mayores ediciones no ocultan sus preferencias ideológicas sino que las explicitan en sus perfiles. Incluimos a continuación una síntesis de las plantillas de presentación en la Tabla II (ver Anexo).

Tal como observamos, el Usuario 1 es quien más cantidad de ediciones ha hecho y más texto aportó al artículo. En su perfil se define explícitamente una orientación provida y cristiana. Según su propia descripción, participa en Wikipedia desde 2009. El Usuario 2 presenta en su descripción una cita de León Trotsky. Tiene plantillas que indican un rol en Wikipedia (verificador, revisor). Los Usuarios 3 y 4 no presentan información relacionada a un posicionamiento explícito sobre el tema. En el primer caso se detallan áreas de incumbencia y se aclara una orientación religiosa particular. Ambos participan activamente de las discusiones: en general las intervenciones del Usuario 3 remarcan procesos colectivos de organización proelección o defienden el uso de ciertas fuentes, mientras el Usuario 4 propone correcciones de estilo y tiene fuerte participación en discusiones, como analizamos a continuación. La Usuaria 5 se define explícitamente como socialista, atea y militante en Wikipedia por los derechos LGTBI. Es la única mujer entre los mayores editores del artículo.

Debemos detenernos brevemente en este punto. Según estimaciones, alrededor del $16 \%$ de las editoras son mujeres (Hill \& Shaw, 2013). Existen dos tipos de brechas de género en Wikipedia: la "brecha de participación", escaso porcentaje de editoras mujeres autodeclaradas, y la "brecha de contenidos", ausencia de perspectiva de género en los contenidos (Pagola, 2016). 


\subsection{Discusiones e incidentes}

Los procesos de edición colectiva que caracterizan a Wikipedia a menudo generan desacuerdos entre los editores. Para el análisis de este apartado partimos del abordaje de los discursos sociales, entendidos estos como hechos sociales e históricos, que operan con cierta independencia de sus sujetos enunciadores. Lo entendemos así como una muestra sincrónica del estado de fuerzas en torno a la definición legítima de un tema, desde la "imposibilidad de la total neutralidad" de un discurso social (neutralidad a la que la enciclopedia apunta a través de los diversos mecanismos nombrados). Angenot (2010) aporta aquí la noción de discurso hegemónico, donde la hegemonía opera en la imposición de categorías en las que se encierran estas luchas, en otras palabras, en la condición de posibilidad de las denominaciones subyacentes a la imposición de sentido.

A través de las discusiones que surgen de la situación puntual del aborto en Argentina, interesa observar los códigos específicos de Wikipedia, en donde los argumentos, justificaciones y hasta insultos se hacen en un lenguaje específico del campo. Cada artículo de la enciclopedia se acompaña por ello de una página de discusión donde se proponen modificaciones y sugerencias, para recibir retroalimentación de otros usuarios. En el caso de Aborto en Argentina, encontramos 17 temas de debate. Presentamos una síntesis en la Tabla III: 
Tabla III

Temas de discusión del artículo: Aborto en Argentina

\begin{tabular}{|l|c|}
\hline Mejoras de contenido/conceptos & 4 \\
\hline Enlaces no disponibles & 3 \\
\hline Fuentes no fiables/no neutrales & 2 \\
\hline Actualizaciones de contenido & 2 \\
\hline Contenido no neutral/no enciclopédico & 2 \\
\hline Mejoras en la estructura del artículo & 2 \\
\hline Contenido no relevante & 1 \\
\hline Datos erróneos & 1 \\
\hline Total & 17 \\
\hline
\end{tabular}

Fuente: elaboración propia, en base a Aborto en Argentina (2018, 3 de octubre)

Tal como anticipamos, uno de los cinco pilares de Wikipedia es "seguir normas de etiqueta". Ello implica respetar formas de cordialidad en el trato, ser receptivo a la opinión de los demás, y argumentar de la manera más franca y transparente posible. Este código de conducta se observa en la mayor parte de las intervenciones presentadas, las cuales llegan en general a posiciones de acuerdo entre los editores.

Destacamos brevemente tres debates referidos a la no-neutralidad del artículo. Lo interesante es ver cómo se discuten conceptos con profunda carga ideológica (como "defensa de los hijos antes de nacer" o la discusión aborto vs. derecho al aborto) y analizar cómo se ponen en juego las reglas de Wikipedia, resaltando un esfuerzo por representar una variedad de puntos de vista en función de su incidencia sobre el tema.

El primer debate "Equilibrar el artículo" es iniciado por el Usuario 4, uno de los revisores más activos. Como vemos en el extracto, la respuesta está basada en la "libertad de agregar" siempre y cuando se "mantenga el equilibrio" que asegura la neutralidad de Wikipedia. 


\section{Imagen 2}

Discusión: Aborto en Argentina

\section{Equilibrar el artículo [editar ] \\ El artículo cita páginas de grupos que promueven el aborto en Argentina. Para equilibrarlo, habría que incluir sitios que promueven la defensa de los hijos antes de nacer. O quizá habría que quitar el link a páginas que promueven el aborto, para no convertir una voz así en una plataforma de propaganda.-___ (discusión) 15:17 19 may 2012 (UTC) \\ No sé a que páginas que «promueven el aborto» te refieres, yo solo veo páginas que promueven el derecho al aborto. Estás en libertad de agregar las paginas pro-vida que quieras, manteniendo el equilibrio. Eliminar páginas pro-elección sería hacer «propaganda» por el bando de los pro-vida. Y la wikipedia es neutral. (discusión) 19:05 1 abr 2013 (UTC)}

Fuente: Aborto en Argentina (2018, 3 de octubre)

El segundo debate "Artículo con calumnias y no neutral (queda en evidencia su postura pro-aborto)", se inicia por un usuario anónimo. El primer comentario es una gran exposición provida, a lo que la respuesta de un editor, además de la neutralidad de la enciclopedia, es de una invalidación del comentario por el anonimato "Por último, tampoco voy a discutir...con una IP ;)” y además:

No sé si se entiende...este es un tema muy complicado del que NO HAY CONSENSO (y que seguramente no lo haya en mucho tiempo), así que si bien cuesta muchísimo escribir un artículo neutral, creo que hay que intentarlo. Y, si eventualmente, la Wikipedia te parece demasiado "abortista", te recomiendo esta "enciclopedia" online ;). (Wikipedia: Aborto en Argentina, s.f)

Redirigiendo al portal de Metapedia, una enciclopedia alternativa, mayormente clon de Wikipedia, declarada como de extrema derecha (Wikipedia: Metapedia, s.f). Estos lenguajes y códigos son compartidos para quienes habitan esta comunidad. 
Un tercer debate es por el uso del término "Persona gestante". En éste, el Usuario 3 plantea que el artículo debería usar esta expresión para incluir las posibilidades de embarazo y aborto de personas transexuales, amparado en la terminología usada en el proyecto de ley, citando como fuente la Cámara de Diputados. Otro usuario lo valida, respaldándose en las fuentes. El Usuario 4 coincide en respetar las fuentes pero agrega que, al tratarse de una enciclopedia, debería utilizarse "el término común". Otro editor contesta que ya habían dado razones para el "término correspondiente", y sobre todo, dos personas habían marcado que el término correcto es "persona gestante". En este debate están en juego posturas ideológicas pero con el eje puesto en el funcionamiento de Wikipedia, en los entramados de editores y usuarios que revisan.

\section{Imagen 3}

Discusión: Aborto en Argentina

Persona gestante. [editar]

Buenas. Creo que es mejor que se use en el articulo el persona gestante también. El mismo proyecto de ley dice "derecho de las mujeres o personas gestantes", la pagina de diputados usa esas palabras en varias oportunidades. Creo que hay que recordar que las personas trans pueden embarazarse, es algo que pienso debería estar en la pagina, imitando lo que sucede en la ley o en diputados. Saludos. (discusión)

Claramente en las citas directas hay que dejar lo que digan las fuentes. En las palabras "propias" del artículo, corresponde el término adecuado persona gestante pues no toda mujer tiene capacidad de gestar y no sólo las mujeres tienen esa capacidad.

Saludos. 07:34 15 jun 2018 (UTC)

Hay que mantener el término usado de modo común. Si una fuente usa "persona gestante" se puede usar ese término según la fuente lo usa. Así, si la fuente dice "mujeres o personas gestantes" se pondrían los dos términos. En el resto de la voz, lo mejor es usar la terminologia común.(discusión) 08:24 15 jun 2018 (UTC)

Ya hay dos usuarios que marcaron que el término correspondiente es el de persona gestante. ¿Cuál sería la razón para no incluir a los trans en nuestro artículo? Que a le parece que hay que usar el término común, pues no. Así no funciona.

El término correspondiente es persona gestante y ya se dieron las razones por las cuales utilizarlo. Que el término más común sea un término erróneo no nos juega a nuestro favor. Saludos. 15:11 15 jun 2018 (UTC)

Fuente: Aborto en Argentina (2018, 3 de octubre) 
Otro elemento para analizar es la cantidad de incidentes, esto es, ediciones registradas como maliciosas por la enciclopedia. Estas movilizan el accionar de bots para revertir cambios, proteger el contenido o limitar la acción de usuarios maliciosos. La mayoría de los filtros antiabuso se activan para prevenir actos de vandalismo, que intentan borrar secciones de texto, añadir contenido inapropiado o agravios. También aquellas "guerras de edición", esto es, ediciones que son disputadas entre usuarios, eliminadas y vueltas a colocar recurrentemente. Encontramos que 63 de los 98 incidentes reportados se produjeron durante 2018, momento de mayor intensidad en la edición del artículo.

Tabla IV

Clasificación de filtros anti abuso: Aborto en Argentina

\begin{tabular}{|l|c|}
\hline Ediciones incorrectas frecuentes & 33 \\
\hline Eliminación de referencias & 15 \\
\hline Usuario nuevo blanqueando artículos & 11 \\
\hline Breves adiciones incorrectas & 10 \\
\hline Frases en mayúsculas & 8 \\
\hline Eliminación de secciones & 6 \\
\hline Eliminación de categorías & 4 \\
\hline Eliminación de plantillas de mantenimiento & 4 \\
\hline Caracteres repetidos & 3 \\
\hline Otras & 4 \\
\hline Total & 98 \\
\hline
\end{tabular}

Fuente: elaboración propia, en base a Aborto en Argentina (2018, 3 de octubre)

\subsection{Uso de fuentes}

En su investigación sobre la revolución egipcia de 2011 en la edición inglesa de Wikipedia, Ford (2012) analiza el rol de los social media y otros recursos de internet como fuentes de información en artículos de actualidad. En tales casos, los artículos se elaboran en simultáneo con los hechos producidos, por lo que pueden producirse conflictos entre el género periodístico y el enciclopédico. Entre los editores este fenómeno ha sido denominado "recentismo", y existen una serie de definiciones para evitar que el contenido quede rápidamente obsoleto o se vuelva irrelevante desde el punto de vista enciclopédico (Saorín, 2017). 
Al tratarse de fenómenos recientes, no se cuenta con la posibilidad de respaldar el contenido en fuentes especializadas o académicas. Prevalece así el uso de fuentes primarias, generalistas o periodísticas, junto con la discusión respecto a su relevancia, parcialidad o veracidad en los contenidos. En relación con lo anterior, Aborto en Argentina cuenta al momento del estudio con 237 referencias. La Figura 4 muestra una síntesis de las mismas, de la cual extraemos algunas conclusiones.

\section{Figura 4}

Tipo de Fuentes: Aborto en Argentina

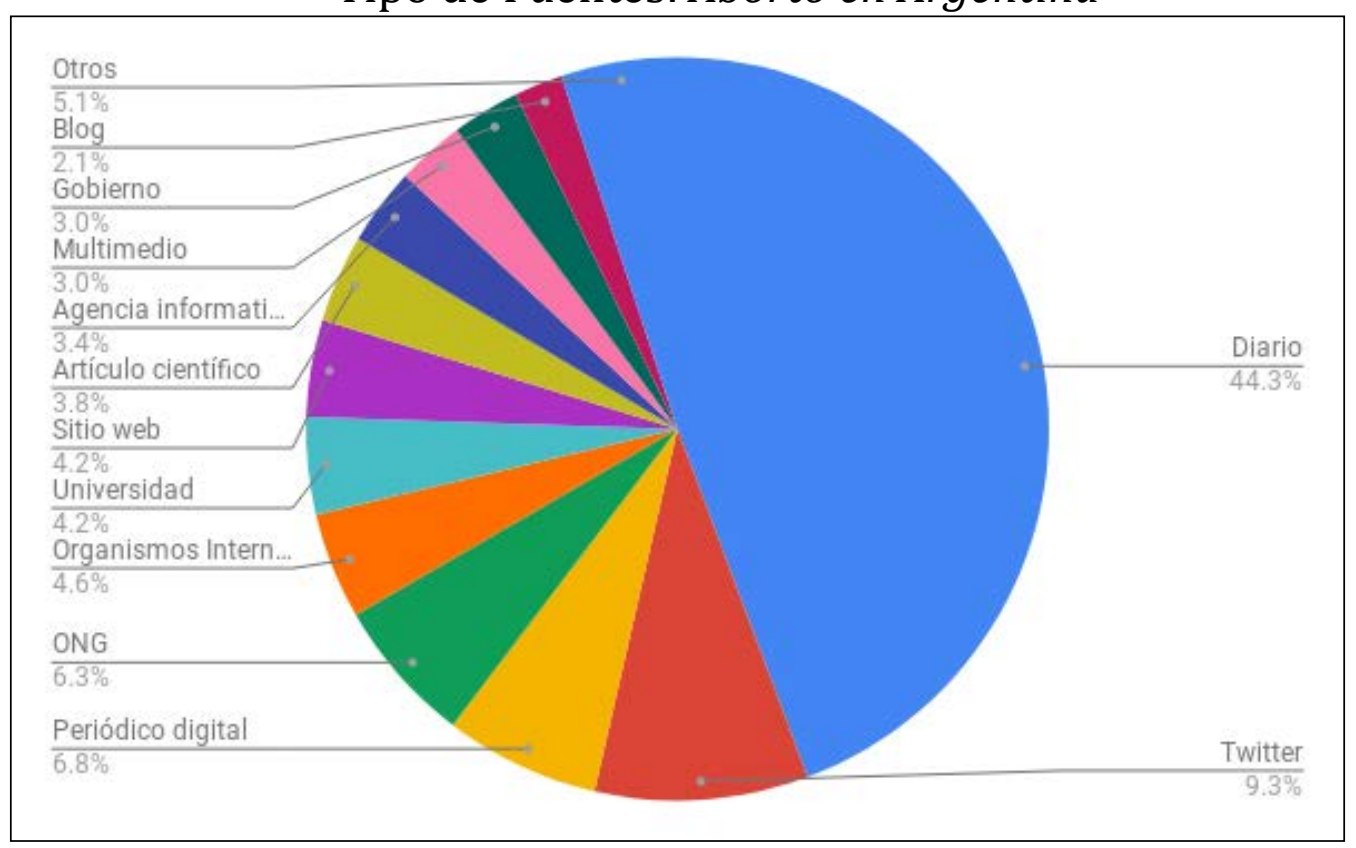

Fuente: elaboración propia, en base a Aborto en Argentina (2018, 3 de noviembre) 
Observamos en primer lugar la pluralidad de fuentes consultadas, destacando la referencia a medios de comunicación digital: diarios, periódicos, agencias informativas y multimedios. Encontramos en este caso una diversidad, que incluye desde medios de tirada masiva a especializados, de alcance nacional o provincial (en menor medida internacionales), e inclusive vinculados con posiciones proelección o provida, como medios partidarios o religiosos. La Tabla V muestra de esta manera que, mientras los medios masivos de alcance nacional se llevan la porción mayoritaria de referencias, medios locales contribuyen enriqueciendo el artículo con particularidades o posicionamientos regionales. Tal preeminencia de los medios de mayor tirada ha sido ratificada en un reciente estudio sobre el conjunto de los artículos de Wikipedia en español y su relación con la prensa generalista (Rodríguez-Mateos \& Hernández-Pérez, 2018).

Si consideramos la cantidad de diarios citados, independientemente de su ponderación, arribamos a un total de 22 medios nacionales, 15 medios provinciales y 3 internacionales. En cuanto a los periódicos digitales, encontramos un total de 11 medios.

\section{Tabla V}

Cantidad de referencias a Diarios: Aborto en Argentina

\begin{tabular}{|l|c|}
\hline Infobae & 16 \\
\hline La nación & 12 \\
\hline Página 12 & 12 \\
\hline Perfil & 8 \\
\hline Clarín & 8 \\
\hline Prensa Obrera & 4 \\
\hline Agencia Católica de Informaciones & 4 \\
\hline Ámbito financiero & 3 \\
\hline La izquierda & 3 \\
\hline Otros nacionales & 14 \\
\hline Provinciales & 18 \\
\hline Internacionales & 3 \\
\hline Total & 105 \\
\hline
\end{tabular}

Fuente: elaboración propia, en base a Aborto en Argentina

(2018, 3 de noviembre) 
Un segundo grupo de fuentes lo encontramos en aquellas gubernamentales, de universidades, u organizaciones internacionales y nacionales sin ánimo de lucro. Se trata en estos casos mayormente de declaraciones en favor o en contra del proyecto legislativo. Además de ellas, otro grupo de referencias corresponden a sitios web en internet y plataformas de redes sociales, principalmente Twitter y blogs. Al igual que en el caso anterior, encontramos aquí posicionamientos, artículos de opinión y campañas. Cabe aclarar que estas fuentes son utilizadas de acuerdo con los principios establecidos por Wikipedia, esto es, solo para corroborar información sobre sí mismos y no para acreditar determinados hechos. Por último, se incluyen artículos científicos revisados por pares, legislación y análisis legislativo, ubicándose estas fuentes en torno al 6\% del total.

\section{Conclusiones}

En el trabajo analizamos la construcción del artículo de Wikipedia Aborto en Argentina, desde su creación en 2009 hasta septiembre de 2018. Nuestro objetivo fue comprender cómo la edición constante del artículo se entrelaza con las luchas políticas de los movimientos sociales a favor y en contra del aborto legal en este país. Si bien la interrupción voluntaria del embarazo ha sido una demanda histórica del feminismo, en el año 2018 ingresó fuertemente en las agendas públicas y mediáticas, de la mano de su tratamiento legislativo y la fuerte movilización social derivada del mismo.

Tal y como pudimos corroborar, el incremento exponencial de ediciones y visualizaciones del artículo en Wikipedia coinciden con los momentos más álgidos del debate suscitado, lo cual evidencia la relevancia de esta plataforma como un espacio de construcción de realidad regido por lógicas específicas. El principio de punto de vista neutral, uno de los pilares que sostienen la enciclopedia, es puesto en juego en el caso analizado de diferentes maneras: en la estructura del artículo, en la explicitación de los sesgos de sus editores, en las discusiones registradas y en la diversidad de fuentes referidas. 
Un análisis de la plataforma que comprende su contenido a partir del rastreo de la sucesión de interacciones que tuvieron lugar entre sus editores permite, de este modo, desmenuzar las tensiones y controversias suscitadas. Es significativo descubrir, en contraposición a otros artículos, una cantidad de ediciones no anónimas, explícitamente ubicadas en posicionamientos provida o proelección. Así, podemos entender al artículo como el resultado de un equilibrio precario entre posturas mayormente opuestas, pero en una apuesta por representar todos los aspectos del debate. En este sentido, la elección de los términos resulta una cuestión central en la lucha por la hegemonía-contra hegemonía discursiva: los conceptos de "persona gestante" o "bebé por nacer" son, entre otros, discutidos entre los usuarios, mientras aquellos fundados en los textos legales cuentan con mayor legitimidad dentro de la enciclopedia.

El artículo seleccionado nos permite, de este modo, analizar ciertas dinámicas generales del funcionamiento de Wikipedia. Definida como una "fábrica de hechos", Wikipedia ocupa un lugar central como referencia y fuente de conocimientos en la actualidad. No exenta de múltiples cuestionamientos, su legitimidad se sostiene en la auditabilidad de sus procedimientos, la deliberación pública en torno a sus reglas y contenidos, así como su horizontalidad y apertura en el proceso de edición, asociado a un modelo no comercial de producción colaborativa en masa. 


\section{Bibliografía}

- ABORTO EN ARGENTINA. (2018, 3 de octubre). En Wikipedia, La enciclopedia libre. Recuperado de https://es.wikipedia.org/w/index.php?title=Aborto_en_ Argentina

- ALAMO, S., BORDOY, G., CHETTO, M., IBAÑEZ, F., MIGLIORINI, A. \& OCAMPO, M. E. G. (2018). \#NiUnaMenos: Big Data para la comprensión de una problemática de género. Actas del I Congreso Internacional de la Asociación Argentina de Humanidades Digitales-AAHD. Universidad de Buenos Aires, Argentina.

- AMNISTÍA INTERNACIONAL. (2018). Aportes de Amnistía Internacional al debate sobre la despenalización del aborto, Argentina. Recuperado de https:// bit.ly/2JGNvbz

- ANGEnOT, M. (2010). El discurso social, los límites de lo pensable y lo decible. Buenos Aires: Siglo XXI.

- ARDÉVOL, E. (2016). Big data y descripción densa. Virtualis, 7(14), 14-38. Recuperado de https://bit.ly/20xrLkp

- ARTÍCULOS CON MÁS EDICIONES. (2018, 3 de octubre). En Wikipedia, La enciclopedia libre. Recuperado de https://es.wikipedia.org/wiki/ Especial:M\%C3\%A1sEdiciones

- BARRANCOS, D. (2007). Mujeres en la sociedad argentina: una historia de cinco siglos. Buenos Aires: Sudamericana.

- BAUWENS, M. (2008). Is something fundamentally wrong with Wikipedia governance processes?. P2P Foundation blog. Recuperado de https://bit. ly/322UQs2

- BELLUCCI, M. (2014). Historia de una desobediencia. Abortoy feminismo. Buenos Aires: Capital Intelectual.

- BENKLER, Y., FARIS, R. \& ROBERTS, H. (2018). Network Propaganda: Manipulation, Disinformation, and Radicalization in American Politics. Cambridge: Oxford University Press. 
- BENKLER, Y., SHAW, A. \& HILL, B. M. (2015). Peer production: A form of collective intelligence. En T. Malone \& M. Bernstein (Eds.), Handbook of Collective Intelligence. Cambridge: MIT Press.

- BENNETT, W. L. (2005). Social movements beyond borders: understanding two eras of transnational activism. En D. Della Porta \& S. G. Tarrow (Eds.), Transnational protestand global activism. Estados Unidos: Rowman \& Littlefield.

- CASTELlS, M. (2007). Communication, Power and Counter-power in the Network Society. International Journal of Communication, 1(1), 238-266. Recuperado de http://ijoc.org/ojs/index.php/ijoc/article/view/46/35

- CONTROPEDIA. (2018). Analysis and visualization of controversies within Wikipedia articles. Recuperado de http://contropedia.net/

- ECHAVARRÍA, C. \& BARD WIGDOR, G. (2013). Frente a la crisis neoliberal, las mujeres se organizan: la experiencia de participación comunitaria de las mujeres de sectores populares en la Argentina. Nomadías, (17), 89-107. doi: 10.5354/0719-0905.2014.29940

- ENCUENTRO NACIONAL DE MUJERES. (2018). Historia del Encuentro. Recuperado de http://encuentrodemujeres.com.ar/historia-del-encuentro/

- FORD, H. (2012). Wikipedia sources: Managing sources in rapidly evolving global news articles on the English Wikipedia. Recuperado de https://bit.ly/2LXZSjK

- FORD, H. (2015). Fact Factories: Wikipedia and the power to represent. (Tesis Doctoral). University of Oxford, Reino Unido.

- HILL, B. M. \& SHAW, A. (2013). The Wikipedia gender gap revisited: Characterizing survey response bias with propensity score estimation. PloS one, 8(6), e65782. doi: 10.1371/journal.pone.0065782

- HINE, C. (2015). Ethnography for the Internet: Embedded, embodied and everyday. UK: Bloomsbury Publishing.

- I PÉREZ, X. G. (2007). Política del disenso: sociología de los movimientos sociales. España: Icaria Editorial. 
- JEMIELNIAK, D. (2014). Common knowledge?: An ethnography of Wikipedia. Stanford: Stanford University Press.

- JUSTO VON LURZER, C. (2017). Esto le puede servir a alguien. Demandas de derechos en el espectáculo televisivo contemporáneo en Argentina. Estudos em Comunicação, (25), 23-52. doi: 10.20287/ec.n25.v1.a03

- KONIECZNY, P. (2010). Adhocratic governance in the Internet age: A case of Wikipedia. Journal of Information Technology \& Politics, 7(4), 263-283. doi: 10.1080/19331681.2010.489408

- LATFEM. (2018, junio 17). \#AbortoLegalYa: cronología de una ley empujada por el feminismo. Recuperado de https://bit.ly/311PknU

- LATOUR, B. Z. (2008). Reensamblar lo social. Una introducción a la teoría del actor-red. Buenos Aires: Manantial.

- LERGA FELIP, M. \& AIBAR PUENTES, E. (2015). Guía de buenas prácticas para el uso docente de Wikipedia en la Universidad. Barcelona: Universitat Oberta de Catalunya.

- MANOVICH, L. (2011). Trending: The promises and the challenges of big social data. En M. K. Gold (Ed.), Debates in the digital humanities, 2. Minnesota: University of Minnesota Press.

- NIELSEN, J. (2006). The 90-9-1 rule for participation inequality in social media and online communities. Recuperado de https://bit.ly/1UDnNCk

- PÁGINA 12. (2018, 12 de abril). Intervención Claudia Piñero en Diputados. Recuperado de https://bit.ly/35jokDY

- PAGOLA, L. I. (2016). Perspectiva de género en espacios de construcción colectiva del conocimiento en entornos virtuales: la brecha de género en Wikipedia. Actas VI Coloquio Interdisciplinario Internacional Educación, Sexualidades y Género. IV Congreso Género y Sociedad. Universidad Nacional de Córdoba, Argentina.

- PEKER, L. (2017). La revolución de las mujeres no era solo una píldora. Villa María: Eduvim. 
- RAYMOND, E. (2001). The cathedral and the bazaar. California: O'Reilly Media.

- REAGLE, J. M. (2010). Good faith collaboration: The culture of Wikipedia. Cambridge: MIT Press.

- RODRÍGUEZ-MATEOS, D. \& HERNÁNDEZ-PÉREZ, T. (2018). Los periódicos españoles como fuente de referencia en Wikipedia. El profesional de la información, 27(6), 1323-1333. doi: 10.3145/epi.2018.nov.15

- ROSENDE, L. \& PERTOR, W. (2018, 9 de agosto). Quienes llevan los pañuelos celestes. Anfibia. Recuperado de https://bit.ly/2pbmjZJ

- SAORÍN, T. (2017). Wikipedismo de actualidad. La enciclopedia escrita desde el periodismo. Anuario ThinkEPI, 11, 191-199. doi: 10.3145/thinkepi.2017.35

- SIN PERMISO. (2018, junio 16). Argentina: La marea verde conquista el derecho al aborto. Dossier. Recuperado de https://bit.ly/33hmr80

- SNEE, H., HINE, C., MOREY, Y., ROBERTS, S. \& WATSON, H. (Eds.). (2016). Digital methods for social science: An interdisciplinary guide to research innovation. Reino Unido: Palgrave Macmillan.

- TILLY, C. (2000). Historical analysis of political processes. En J. Turner (Ed.), Handbook of Sociological Theory. Nueva York: Plenum.

- TILLY, C. \& WOOD, L. J. (2010). Los movimientos sociales, 1768-2008: Desde sus orígenes a Facebook. Barcelona: Crítica.

- VAN DIJCK, J. (2016). La cultura de la conectividad: una historia crítica de las redes sociales. Buenos Aires: Siglo Veintiuno.

- WIKIMEDIA FOUNDATION (WMF). (2018). Wikimedia Foundation Vision. Recuperado de https://wikimediafoundation.org/about/vision/ 
- WIKIMEDIA FOUNDATION (WMF). (2018, 3 de noviembre). Wikimedia Statistics. Recuperado de https://stats.wikimedia.org

- WIKIPEDIA: POLÍTICAS Y CONVENCIONES. (2018, 3 de octubre). En Wikipedia, La enciclopedia libre. Recuperado de https://es.wikipedia.org/wiki/ Wikipedia:Pol\%C3\%ADticas_y_convenciones

- ZANOTTI, A. (2014). Software y Cultura libre en Argentina: Experiencias y convergencias. Hipertextos, 3(2), 69-93. Recuperado de https://ri.conicet.gov. ar/handle/11336/37050 
Síntesis de plantillas de presentación

\begin{tabular}{|c|c|c|c|c|}
\hline Usuario 1 & Usuario 2 & Usuario 3 & Usuario 4 & Usuario 5 \\
\hline $\begin{array}{l}\text { Este wikipedista } \\
\text { es cristiano } \\
\text { católico. } \\
\text { Este usuario } \\
\text { tiene un } \\
\text { pensamiento } \\
\text { político } \\
\text { demócrata } \\
\text { cristiano. } \\
\text { Q } \\
\text { Este usuario es } \\
\text { provida } \\
\text { y defiende el } \\
\text { derecho a vivir. }\end{array}$ & $\begin{array}{l}\text { «Quien se } \\
\text { arrodilla } \\
\text { ante el hecho } \\
\text { consumado } \\
\text { es incapaz de } \\
\text { enfrentar el } \\
\text { porvenir» León } \\
\text { Trotski. } \\
\\
\text { Este es un } \\
\text { usuario } \\
\text { toconfirmado en } \\
\text { la Wikipedia en } \\
\text { español. } \\
\text { a } \\
\text { Este usuario es } \\
\text { verificador en } \\
\text { Wikipedia en } \\
\text { español. } \\
\text { aste usuario está } \\
\text { autoverificado } \\
\text { en Wikipedia en } \\
\text { español. }\end{array}$ & \begin{tabular}{|l} 
Trabajo en \\
filosofía, bioética, \\
cristianismo \\
y apicultura, \\
entre otras \\
ocupaciones. \\
Este usuario es \\
reversor1 en la \\
Wikipedia en \\
español.
\end{tabular} & $\backslash_{-}(.)_{-} /$ & $\begin{array}{l}\text { Este wikipedista } \\
\text { es socialista. } \\
\text { este wikipedista } \\
\text { es ateo. } \\
\text { Este wikipedista } \\
\text { está a favor de los } \\
\text { derechos de gais } \\
\text { y lesbianas. } \\
\text { Yo colaboro en } \\
\text { el Wikiproyecto } \\
\text { LGBT. } \\
\text { E } \\
\text { a } \\
\text { Este usuario es } \\
\text { reversora en } \\
\text { wikipedia en } \\
\text { español. } \\
\text { Esta } \\
\text { Esta wikipedista } \\
\text { cree que el } \\
\text { pastafarismo y } \\
\text { el creacionismo } \\
\text { son igualmente } \\
\text { posibles. }\end{array}$ \\
\hline
\end{tabular}

* Los nombres de los usuarios fueron modificados Fuente: elaboración propia, en base a Aborto en Argentina (2018, 3 de octubre) 


\section{Biografías}

\section{Paloma Rubin}

Universidad Nacional de Villa María, Argentina

orcid: 0000-0002-5222-9523

palomarubin12@gmail.com

Estudiante avanzada de Licenciatura en Sociología en el IAP Ciencias Sociales. Activista en temas de género.

\section{Agustín Zanotti}

Universidad Nacional de Córdoba/ CONICET

Universidad Nacional de Villa María, Argentina

orcid: 0000-0002-7662-7593

azanotti@unvm.edu.ar

Doctor en Estudios Sociales de América Latina. Docente Investigador en la Facultad de Ciencias Sociales, Universidad Nacional de Córdoba, y el IAP Ciencias Sociales, Universidad Nacional de Villa María, Argentina. Investigador en CONICET del Centro de Investigaciones y Estudios sobre Cultura y Sociedad. 